\title{
Risk analysis in the chemical industry: an urea-formaldehyde resins case
}

\author{
A. Quintana, L. López-Doval, R. Rodríguez, J. A. Souto \\ \& J. J. Casares \\ Department of Chemical Engineering, \\ University of Santiago de Compostela, Santiago de Compostela, Spain
}

\begin{abstract}
The fast evolution of the industry technology as a whole and, particularly, of that associated to the chemical processes, its rapid growth and the resulting increase in chemical products inventories in industrial plants and transport, has increased the probability of severe accidents, and the magnitude of their consequences. The purpose of this study is to verify the application of a regulation based on deterministic methods to guarantee the safety of the environment and inhabited areas around an industrial facility. The study is focused on a chemical plant for resins production, where hazardous chemical substances are processed and stored, such as methanol, formaldehyde, vinyl acetate monomer (VAM) and phenol. The HAZOP deterministic methodology is used to analyse potential accidents and, afterwards, to determine the magnitude of their consequences.

In this study, accidents that would create a toxic cloud and its following dispersion into the atmosphere are considered. Therefore, a regulatory atmospheric dispersion model has been applied. Depending on the type of accident, the chemical substances involved and the atmospheric conditions of the area, the software calculates how surrounding areas are affected. Likewise, the concentration of toxic substances at a certain distance can be determined in order to evaluate the percentage of population affected by the dispersion of the toxic cloud.
\end{abstract}

Keywords: hazardous chemical, consequence analysis, risk analysis, hazard analysis, chemical accident. 


\section{Introduction}

Great changes have occurred over the last century, one of them being the rapid expansion of the chemical process industry. These changes took place due the advancement of science, the development of new technologies and the rising standards of living. Unfortunately, the appearance of new processes and products in a more and more demanding global market, have increased the risks associated with the production process.

The analysis of the hazards involved and the determination of the effects caused by accidents and their quantitative evaluation is becoming a necessity both for the protection of the environment as well as the health of the people presumably affected preventing possible accidents in order to avoid their effects.

Risk analysis is focused in the identification and evaluation of possible accidents in a process plant, considering the vulnerability and their consequences, as damages in human population, environment, and profits.

From this specific identification, a list of possible accidents should be established and related to the different activities and units in the plant. After that, an evaluation of possible consequences is required.

\section{Methodology}

A risk analysis methodology should be coherent with the main goals of the severe accidents regulation [1]: prevention of the accidents and limitation of their consequences. Therefore, this general methodology is divided in two main parts,

a) Identification of the risks associated to the industrial activities, by the application of HAZOP methodology (Vílchez et al. [2]), and

b) Definition of the systems and tools required to risks control, as a result of the analysis of consequences.

Identification of risks should include,

- Plant site and the safety of its activities.

- Chemical species (from the risk regulations), including quantities, properties, toxicological risks, and pressure and temperature conditions.

- HAZOP methodology for risk identification: In this method, the probability of accidents increases with the deviations of the operational conditions from the normal operation (Casal et al. [3], Dirección General de Protección Civil [4]).

As the main result, information about the plant conditions and the control systems required to prevent undesirable situations is obtained.

Once the risks are identified, an evaluation of the consequences of accidents is considered. From each different phenomenon associated to accidents (fires, explosions, fugitive emissions), a set of physical parameters is considered to evaluate the phenomena in terms of vulnerability; typically, pressure, concentration, and thermal radiation. An evaluation of consequences is based in the estimation of the values that can be achieved for these physical parameters.

As the main result, risk zones around the plant can be defined, depending on the possible damages of these physical parameters over the population, environment, and economy. 
The estimation of the physical parameters is achieved by the application of a simulation tool to different possible accidents. In this work, atmospheric risks are considered, so ALOHA (Area Local of Hazardous Atmospheres) is applied (US EPA and NOAA) [5].

ALOHA is focused on the simulation of the estimation and dispersion of fugitive emissions of hazardous substances. Therefore, other accidents as fires and explosions are not considered here. Two different atmospheric dispersion models are considered: A Gaussian model (Zannetti [6], Jacobson [7]) and a heavy gases model. Both models estimate the chemical products concentrations depending on the site location, atmospheric conditions, and origin of the fugitive emission. The selection of the model depends on the molecular weight of the substance, emission flow and temperature.

\section{Study case}

The methodology explained above has been applied to the analysis of the atmospheric risk associated to a process plant of phenol-formaldehyde and ureaformaldehyde resins (namely, PRP). This plant is located close to a small town shown in figure 1 , with a population of approximately 10,000 . The annual production of phenol-formaldehyde and urea-formaldehyde resins of the plant under study are 3,000 and 200,000 $\mathrm{t}$ respectively.
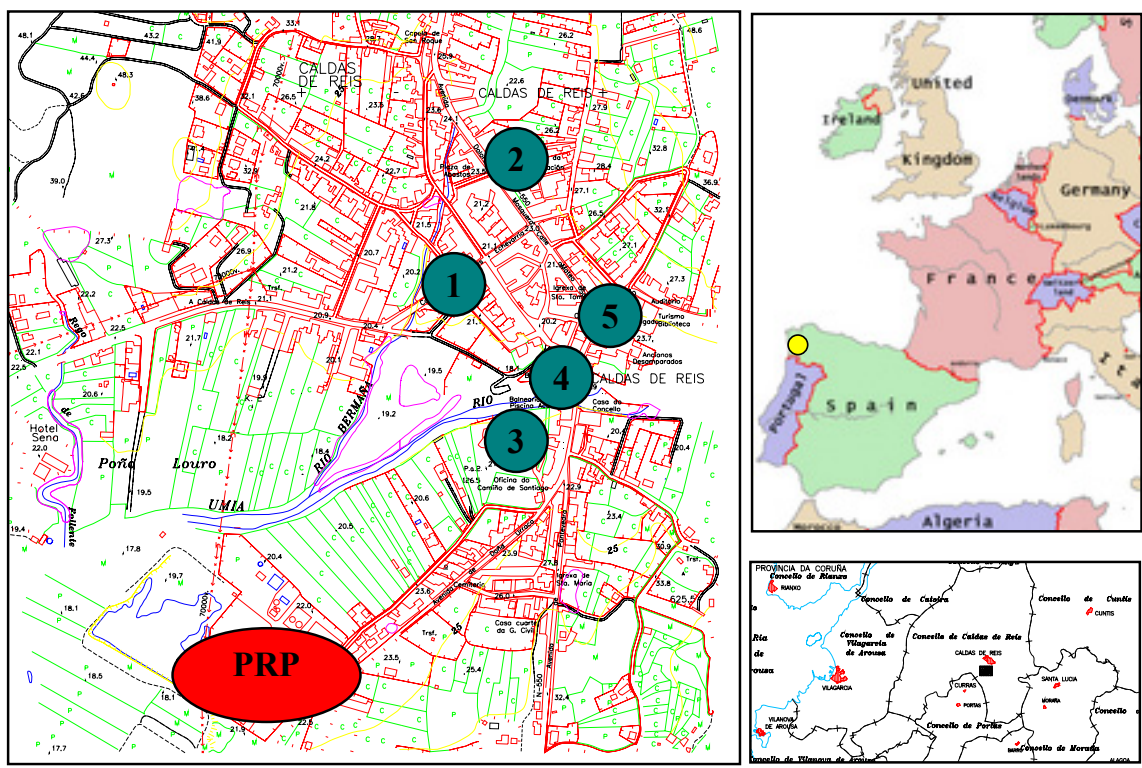

Figure 1: Site map of the PRP plant considered in the study, showing the town centre and different zones (from 1 to 5) affected in the scenarios considered. 
Two main lines in the process can be considered, fig. 2, resins and formaldehyde productions, which are used in other parts of the process. Formaldehyde is produced in a catalytic bed reactor with a gaseous feed of air and methanol at $315-385^{\circ} \mathrm{C}$, at moderate pressure. This reaction is catalyzed by iron and molybdenum oxides.

$$
\mathrm{CH}_{3} \mathrm{OH}+\frac{1}{2} \mathrm{O}_{2} \rightarrow \mathrm{CH}_{2} \mathrm{O}+\mathrm{H}_{2} \mathrm{O}
$$

After that, the products are absorbed in water. During the whole process, it is important to keep the methanol concentration in air under the explosive limit (Walker [8]).
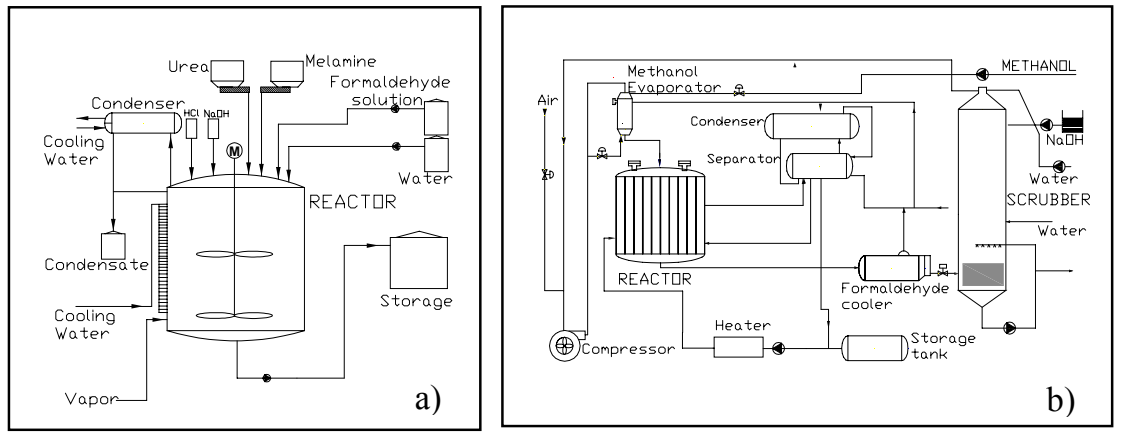

Figure 2: $\quad$ Flow diagram of the main processes identified in the PRP plant under study. a) Polymerization process. b) Synthesis of formaldehyde.

The typical polymerization process (fig. 3) for resins production is performed in a catalytic discontinuous stirred tank reactor, with a feed of formaldehyde and phenol or urea, following the highly exothermic reaction (Kumpinsky [9] and Lu et al. [10]).
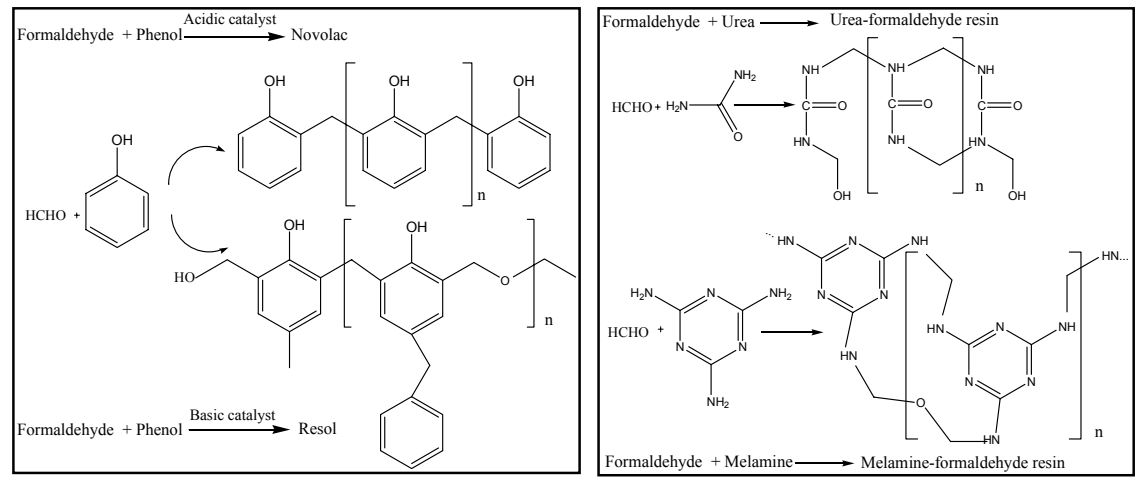

Figure 3: Typical reactions for the synthesis of formaldehyde resins. 
Temperature must be kept at $100{ }^{\circ} \mathrm{C}$ during 2 hours, so cooling of a products recycling is applied. Any failure in stirring, cooling, and reactants feeding, can drive to an uncontrolled state of the process.

Once the main plant processes are identified and following the thresholds established for hazardous substances (European Union [11]), the following chemical species were adopted for our study: pure methanol, formaldehyde $(37 \%)$, and phenol $(80 \%)$ as shown on table 1 .

Table 1: Relationships among the substances, processes, amount stored, and legal threshold identified in the PRP plant under study.

\begin{tabular}{|l|l|}
\hline Hazardous substances & \multicolumn{1}{c|}{ Processes } \\
\hline Methanol & Formaldehyde production \\
\hline Formaldehyde (37\%) & Resins production \\
\hline Phenol $(80 \%)$ & Resins production \\
\hline VAM & Resins production \\
\hline
\end{tabular}

In addition, although the amount of vinyl acetate monomer (VAM) used in the production of vinyl acetate resins is lower than its legal threshold $(50,000 \mathrm{t}$, European Union [11]) to be considered as hazardous, it will be taken into account in order to check it in this study.

Following the process analysis, HAZOP methodology is applied in order to identify possible accidents in the plant.

The consequences analysis was focused in the fugitive atmospheric emissions (FAE) that ALOHA can consider. From a detailed study, the most dangerous typical scenarios of FAE were determined, involving storage tanks and tankers, as follows,

a) Rupture of an output line in a tank,

b) Spill during a tanker feeding.

c) Puncture in a tank.

As atmospheric conditions, the most and least favourable were selected. In this case, the worst scenarios correspond to the summertime, when the evaporation of the spill is higher due to the hot temperatures. Atmospheric stability is defined by the Pasquill class (Zannetti [6]). Therefore, typical meteorological conditions in the region were selected as shown in table 2.

Although the typical conditions in the region correspond to the Pasquill class $\mathrm{D}$, a less favourable condition (strong stability, Class F) for the emissions dispersion was considered too. In this case, because the strong stability is associated to low winds, an artificial reduction in wind speed was applied.

From the simulation of the possible scenarios at different atmospheric conditions, summertime toxic clouds are the most dangerous because of the higher amount of emitted substances. However, because of the typical NE winds in this season, the toxic cloud would tend to cover over sparsely populated areas, far from the emissions source. On the other hand, during wintertime the SW winds would transport the toxic cloud towards the town centre. 
Table 2: $\quad$ Typical values of meteorological parameters in January and July to be applied in the ALOHA simulations.

\begin{tabular}{|l|l|l|}
\hline & January & July \\
\hline Mean temperature $\left({ }^{\circ} \mathrm{C}\right)$ & 10.1 & 24.7 \\
\hline \multirow{2}{*}{$\begin{array}{l}\text { Wind speed }(\mathrm{m} / \mathrm{s})-\text { Pasquill } \\
\text { class stability }\end{array}$} & $3 \mathrm{~m} / \mathrm{s}-\mathrm{D}$ & $5 \mathrm{~m} / \mathrm{s}-\mathrm{D}$ \\
\cline { 2 - 3 } & $1.3 \mathrm{~m} / \mathrm{s}-\mathrm{F}$ & $1.9 \mathrm{~m} / \mathrm{s}-\mathrm{F}$ \\
\hline Wind direction & $\mathrm{SW}$ & $\mathrm{NE}$ \\
\hline Moisture (\%) & $84 \%$ & $94 \%$ \\
\hline Cloudiness & Covered & Clear sky \\
\hline Roughness (m) & \multicolumn{2}{|c|}{0.3 Open Country } \\
\hline
\end{tabular}

Note: For wind speed and atmospheric stability, the most unfavourable conditions (low winds and strong stability) were considered.

From the potentially most dangerous scenarios, in this study two different cases were assumed,

a) A spill of VAM during unloading operations, and,

b) A puncture in a formaldehyde tank.

Both cases were simulated and the Action and Alert Zones were determined; in addition, evolution of the pollutants concentrations at the most sensible sites around the PRP plant were estimated.

\subsection{Spill of VAM during unloading operations}

A broken hose in the discharge of a $32 \mathrm{~m}^{3}$ VAM tanker is considered, with a spill in the discharge zone. The spill time is $5 \mathrm{~min}$., and the spill amount is $8,121 \mathrm{~kg}$ of VAM.

The ALOHA dispersion results show an Alert Zone at $930 \mathrm{~m}$ from the accident, and an Action Zone at $103 \mathrm{~m}$. The first one affects the town centre, therefore two control points (1 and 2) are considered. Figure 4 shows the evolution of VAM concentration along the first hour at these control points; significant VAM levels are achieved (outdoor concentrations close to $14 \mathrm{ppm}$ ), showing that VAM should be studied for consideration as a possible chemical to be included in any analysis.

\subsection{Puncture in a formaldehyde tank}

In this case, a formaldehyde tank with a capacity of $198 \mathrm{~m}^{3}$ can be punctured, due to a mechanical failure, corrosion, wrong design, etc. A hole of 4" at $1.5 \mathrm{~m}$ above ground level is considered.

From the ALOHA simulation, figure 5 shows the evolution of formaldehyde concentration along the first hour, at three different points: two local hotels (sites 3 and 4) and a local hospital (site 5), located at the map in figure 1.

The Aloha simulation obtains the results shown in figure 5, for the evolution of formaldehyde concentration along the first hour at three different sites $(3,4$ and 5). 
The Action and the Alert Zones go as far as $625 \mathrm{~m}$ and 3,600 m, respectively from the plant, affecting the two hotels (sites 3 and 4) and a local hospital (site 5).

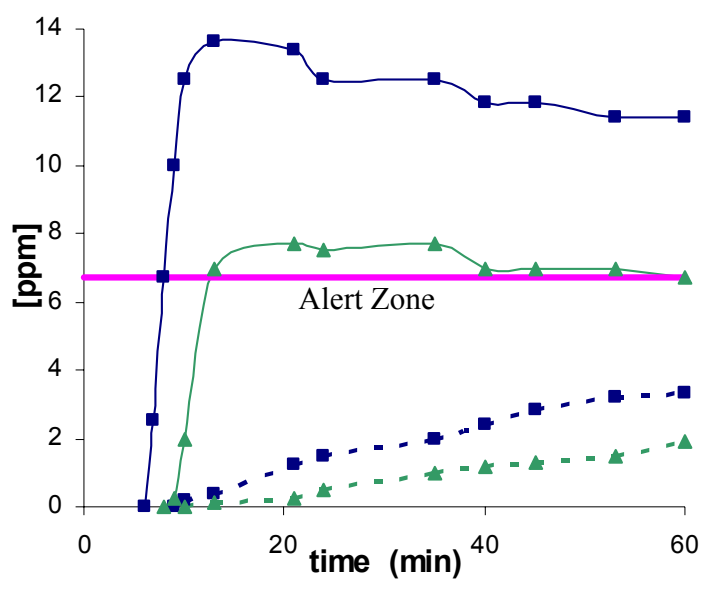

Figure 4: Evolution of VAM concentration with time at specified points 1 (square) and 2 (triangle). Dot and solid lines represent indoor and outdoor concentration, respectively.

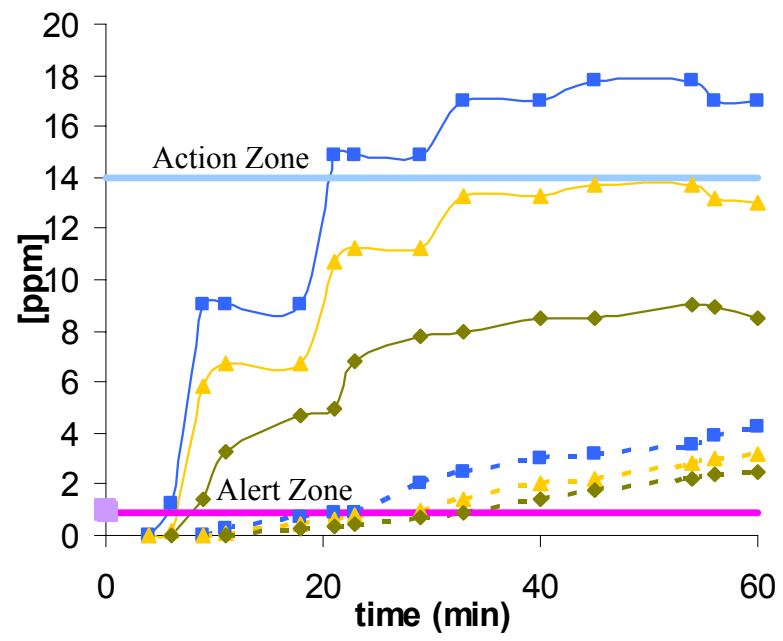

Figure 5: Evolution of formaldehyde concentration with time at specified points 3 (square), 4 (triangle) and 5 (rhombus). Dot and solid lines represent indoor and outdoor concentration, respectively. 


\section{Conclusions}

The use of HAZOP methodology, combined with the application of ALOHA, for the evaluation fugitive atmospheric emissions risks in a phenolformaldehyde and urea-formaldehyde resins plant (PRP) is shown. The simulation of two different scenarios with the most unfavourable meteorological conditions is done.

From the spill of VAM during unloading operations, the estimated pollutant concentration evolution shows that the town centre is included in the Alert Zone. As the current legal pollutants' thresholds do not include VAM as a hazardous substance to be evaluated in this PRP plant, the simulation shows that the thresholds should be reviewed.

In addition, even a fugitive emission of formaldehyde from a hole in a tank should be a scenario to be analyzed in future legal requirements for operation of the plant, due to the proximity of sensible sites.

\section{Acknowledgement}

This work is supported by Xunta de Galicia, under Project PGIDIT05TAM00201CT.

\section{References}

[1] Dirección General de Protección Civil, Methodologies for the risk analysis: A general view. Ministerio del Interior. Madrid, 1994. (in Spanish).

[2] Vílchez, J.A., Baraza, X., Chatris, J.M., El nuevo Informe de Seguridad para la prevención de accidentes graves. Ingeniería Química, 416, pp. 160-168, 2004.

[3] Casal, J., Montiel, H., Planas, E. \& Vilchel, J.A., Identificación de peligros, Ed. UPC: Barcelona, pp 41-78, 1999.

[4] Dirección General de Protección Civil, Qualitative methods for risk analysis. Ministerio del Interior. Madrid, 1994 (in spanish).

[5] U.S. EPA, NOAA (March 2004), ALOHA (Areal Locations of Hazardous Atmospheres) User's Manual, CAMEO web site, http://www.epa.gov.

[6] Zannetti, P., Air Pollution Modeling: Theories, Computational Methods and Available Software, Computational Mechanics Publications, Van Nostrand Reinhold, New York, 1990.

[7] Jacobson, M.Z., Atmospheric Pollution: History, Science and Regulation. Cambridge University Press, Cambridge, 2002.

[8] Walker, J.F., Formaldehyde, American Chemical Society Monograph Series. Reinhold Publishing Co, New York, 1964.

[9] Kumpinsky, E. A study on resol-type phenol-formaldehyde runaway reactions. Ind. Eng. Chem. Res., 33, pp. 285-291, 1994. 
[10] Lu, K-T., Luo, K-M., Lin, S-H., Su, S-H., Hu, K-H., The acid-catalyzed phenol-foemaldehyde reaction: Critical Runaway Conditions and Stability Criterion. Process Safety and Environmental Protection, 82 (B1), pp. 3747, 2004.

[11] European Union, 2003. European Parliament and Council Directive 2003/105/EC of 16 December 2002 amending Council Directive 96/82/EC on the control of major accident hazards involving dangerous substances. Official Journal L 345, 31.12.2003, 97-105. 